\title{
In vitro Complexation of Olmesartan Medoxomil with Dapagliflozin, Vildagliptin and Metformin
}

\author{
Fahima Aktar ${ }^{1}$, Md. Zakir Sultan ${ }^{2}$ and Mohammad A. Rashid ${ }^{1}$ \\ ${ }^{1}$ Department of Pharmaceutical Chemistry, Faculty of Pharmacy, University of Dhaka, Dhaka1000, Bangladesh \\ ${ }^{2}$ Centre for Advanced Research in Sciences, University of Dhaka, Dhaka-1000, Bangladesh
}

(Received: May 20, 2019; Accepted: October 24, 2019; Published (web): December 19, 2019)

\begin{abstract}
Drug-drug interactions have been a serious concern for pharmacokinetics, pharmacodynamics and pharmacological profiles of therapeutic agents. The aim of this study was to carry out interactions of olmesartan medoxomil with dapagliflozin, vildagliptin and metformin, which were confirmed by TLC, HPLC and FT-IR. The newly formed complexes showed characteristic thermochemical properties in differential scanning calorimetry (DSC) and thermo gravimetric analysis (TGA). In TLC, three spots from the three complexes were found to be different from their precursor drugs. In HPLC chromatograms, the $\mathrm{R}_{\mathrm{t}}$ (retention time) of the pure olmesartan medoxomil, dapagliflozin, vildagliptin and metformin were found to be different from their respective complexes. The FT-IR spectra obtained for drug-drug interactions were seen to demonstrate new pattern of peaks compared to pure drugs. The DSC and TGA thermograms of olmesartan medoxomil, dapagliflozin, vildagliptin and metformin were also found to be different from their complexes. All these variations from parent compounds indicated the formation of new complexes.
\end{abstract}

Key words: Drug-drug interaction, olmesartan medoxomil, dapagliflozin, vildagliptin, metformin, TLC, HPLC, FT-

IR, DSC, TGA.

\section{INTRODUCTION}

Drug-drug interactions are important reasons of medication errors. It is estimated that drug interaction results $\sim 30 \%$ of all adverse drug reactions. In hospitalized patients, it occurs about 30\% and for ambulatory patients around $70.3 \%{ }^{1}$ It can be defined as the modification of the effects of one drug (i.e., the object drug) by the prior or concomitant administration of another drug. ${ }^{2}$ Drug-drug interactions are of serious concern in patients who are receiving multi-drug therapy, that cause an increased risk of health problems even in hospitalized patients. ${ }^{3}$

The extent of the drug interactions is a global problem which increases extensively with increase in population of patient and as the number of medications increases. ${ }^{4}$

Correspondence to: Mohammad A. Rashid

Tel.: +88-02-9661900-73, Extn. 8137

Fax: +88-02-9667222

E-mail: r.pchem@yahoo.com

Dhaka Univ. J. Pharm. Sci. 18(2): 271-280, 2019 (December) DOI: https://doi.org/10.3329/dujps.v18i2.44467
Now-a-days diabetes outbreak is in epidemic form. International Diabetes Federation reports that diabetes affects about 382 million people world-wide and it is estimated that this number will raise to 592 million by $2035 .{ }^{5}$ Diabetes is now the leading cause of many serious complications such as cardiovascular, renal and other serious comorbidities. ${ }^{6}$ The distinctive properties of diabetes mellitus are chronic hyperglycemia, microvascular (e.g. retinopathy, nephropathy and neuropathy) as well as the macrovascular (e.g. coronary artery disease (CAD), hypertension (HT), atherosclerosis and stroke) pathologies with more than 17.5 million deaths globally which furthermore attributable to cardiovascular complications. ${ }^{7}$ Diabetes is undoubtedly one of the most challenging health problems in the $21^{\text {st }}$ century. ${ }^{8}$ Hypertension in diabetic patient is also one of the major and common health problems which is frequently difficult to treat and results significant morbidity and mortality. The frequency of hypertension in diabetic people is 
probably 1.5-2.0 times more than in the general people. ${ }^{9}$ The combined presence of hypertension and diabetes affect same major target organs and responsible for left ventricular hypertrophy and coronary artery disease, decrease in renal function, the development of diabetic retinopathy and cerebral diseases. $^{10}$

Olmesartan medoxomil, a prodrug, is hydrolyzed to olmesartan during absorption from the gastrointestinal tract. It is a selective $\mathrm{AT}_{1}$ subtype angiotensin II receptor antagonist antihypertensive agent. ${ }^{11}$ Chemically, olmesartan medoxomil is $1 \mathrm{H}$ imidazole-5-carboxylic acid, 4-(1-hydroxy-1methylethyl)-2-propyl-1-[[2'-(1H-tetrazol-5-yl)[1,1'biphenyl]-4-yl]methyl]- (5-methyl-2-oxo-1,3-dioxol4-yl)methyl ester. It is practically insoluble in water and sparingly soluble in methanol. ${ }^{11}$ The structure of olmesartan medoxomil is shown in figure 1.

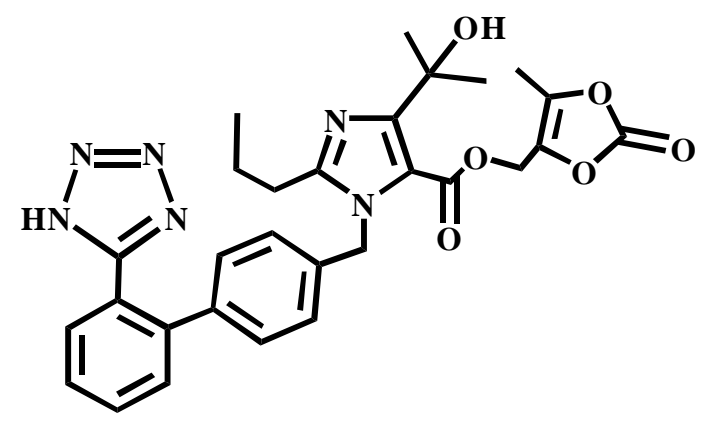

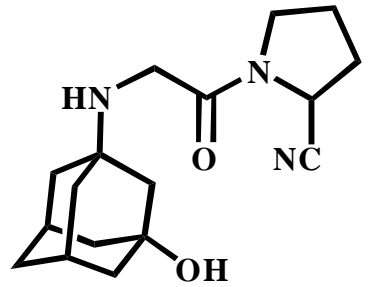

Vildagliptin, Mol. Wt.: 305.42

Olmesartan medoxomil, Mol. Wt.: 558.59

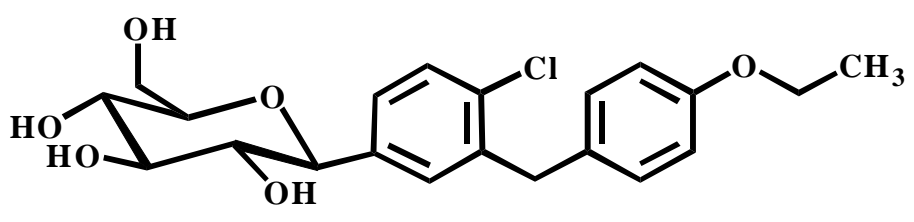

Dapagliflozin, Mol. Wt.: 408.90

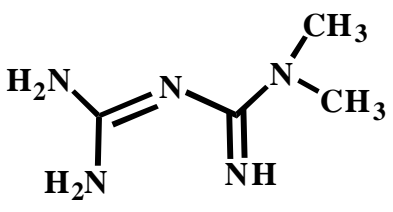

Metformin, Mol. Wt.: 129.16

Figure 1.Structure of olmesartan medoxomil, dapagliflozin, vildagliptin and metformin.

Dapagliflozin (Figure 1), a selective sodiumglucose cotransporter-2 inhibitor, reduces renal glucose re-absorption in an insulin-independent manner. It is soluble in ethanol and DMSO. It significantly reduces the development of hyperglycemia. It could improve the insulin sensitivity, reduce $\beta$-cell mass and the development of impaired pancreatic function. ${ }^{12}$ Vildagliptin (Figure 1) is an oral antihyperglycemic agent of the new dipeptidyl peptidase-4 (DPP-4) inhibitor class of drugs. It inhibits the inactivation of and glucagon-like peptide-1 (GLP-1) and gastric inhibitory polypeptide
(GIP) by DPP-4, allowing GLP-1 and GIP to potentiate the secretion of insulin in the beta cells and suppress glucagon release by the alpha cells of the islets of Langerhans in the pancreas. ${ }^{13}$ It is soluble in water. Metformin (Figure 1) is a biguanide derived antihyperglycemic agent used for treating noninsulin-dependent diabetes mellitus (NIDDM). It improves glycemic control by decreasing hepatic glucose production, as well as decreasing glucose absorption and increasing insulin-mediated glucose uptake. Another well-known benefit of this drug is modest weight loss. ${ }^{14}$ 
This paper describes the formation of complexes of olmesartan medoxomil with dapagliflozin, vildagliptin and metformin $\mathrm{HCl}$, namely olmesartan medoxomil-dapagliflozin complex (OD), olmesartan medoxomil-vildagliptin complex $(\mathrm{OV})$ and olmesartan medoxomil-metformin $\mathrm{HCl}$ complex (OM). To confirm the formation of new complexes TLC, HPLC and FT-IR experiments were carried out followed by DSC analysis and TGA.

\section{MATERIALS AND METHODS}

Materials. Olmesartan medoxomil (potency 99.98\%), Dapagliflozin (potency 99.98\%), Vildagliptin (potency 99.99\%), Metformin $\mathrm{HCl}$ (potency 99.97\%) were kind gifts from Incepta Pharmaceuticals Ltd., Dhaka, Bangladesh. HPLC grade methanol, acetonitrile and chloroform were purchased from Sigma Aldrich, Germany. Nanopure water was prepared by Opurite (PM00723). TLC plate (HSF-254) was purchased from Merck, Germany.

Methods. The drug-drug complexes of olmesartan medoxomil were synthesized according to mole ratios. Equal volumes of $(20 \mathrm{ml})$ of methanol solution of $0.5 \mathrm{mM}$ drugs were prepared by taking $0.279 \mathrm{~g}$ of olmesartan medoxomil, $0.204 \mathrm{~g}$ of dapagliflozin, $0.152 \mathrm{~g}$ of vildagliptin and $0.082 \mathrm{~g}$ of metformin $\mathrm{HCl}$ separately and then drugs were added gradually with stirring followed by changing $\mathrm{pH}$ and heated at $60^{\circ} \mathrm{C}$ for $24 \mathrm{hrs}$. The solutions were then filtered and left at room temperatures.

\section{Analysis of complexes}

TLC. To observe the formation of complexes, TLC was carried using methanol-chloroform (40:60) as mobile phase.

HPLC. RP-HPLC was performed on a $\mathrm{C}_{18}$ column $(5 \mu \mathrm{m}$ particle size, $25 \mathrm{~nm} \times 46 \mathrm{~nm}$ i.d) for estimation of drug content and their related substances. The chromatographic analyses were performed in isocratic mode comprising the mixture of acetonitrile and $15 \mathrm{mM}$ phosphate buffer in the ratio of $60: 40 \mathrm{v} / \mathrm{v}$ and at a flow rate of $1.0 \mathrm{ml} / \mathrm{min}$.
The eluate was monitored through UV detection at $254 \mathrm{~nm}$.

DSC thermogram. DSC thermograms were obtained from the DSC instrument, (model: DSC 60, Shimadzu, Japan). The thermograms were taken in aluminium sealed pan at the temperature range of 30$300^{\circ} \mathrm{C}$, where temperature rising rate was $10^{\circ} \mathrm{C} / \mathrm{min}$ in nitrogen gas at a flow rate of $20 \mathrm{ml} / \mathrm{min}$. All the complexes and pure standard drugs were studied.

TGA. TGA were carried out in TGA $50 \mathrm{H}$, Shimadzu, Japan. The thermograms were taken in aluminium pan at the temperature range of 25-600 ${ }^{\circ} \mathrm{Cwith}$ hold time $5 \mathrm{~min}$. The temperature rising rate was kept at $10{ }^{\circ} \mathrm{C} / \mathrm{min}$ and the nitrogen gas flow rate was at $10 \mathrm{~mL} / \mathrm{min}$. The thermograms of all the complexes and standard drugs were recorded under same conditions.

FT-IR. Standard drug and samples pellets were prepared with appropriate quantity of $\mathrm{KBr}$ (usually in the ratio of 100: 0.1) by mixing and grinding in an agate mortar. Pellets were made with about $100 \mathrm{mg}$ mixture. FT-IR spectra were recorded with FT-IR 8400S (Shimadzu) spectrophotometer in the range of $4000-400 / \mathrm{cm}$ (resolution: $4 / \mathrm{cm}$, number of scans: $30)$.

\section{RESULTS AND DISCUSSION}

Both crystalline and amorphous drug complexes were obtained. To prove the complexation, TLC was carried in methanol-chloroform in the ratio of 40:60. Single spot from the three complexes which were different from their precursor drugs were found (Table 1). Each spot indicated the presence of a new complex.

In HPLC chromatograms, the $\mathrm{R}_{\mathrm{t}}$ (retention time) of the pure olmesartan medoxomil, dapagliflozin, vildagliptin, metformin were found to be $3.59 \mathrm{~min}$, $3.80 \mathrm{~min}, 3.21 \mathrm{~min}, 2.50 \mathrm{~min}$, respectively. The complexes $\mathrm{OD}, \mathrm{OV}$ and $\mathrm{OM}$ showed $\mathrm{R}_{\mathrm{t}}$ at $2.87 \mathrm{~min}$, $9.37 \mathrm{~min}$ and $9.77 \mathrm{~min}$, respectively, which were different from the retention times of their parent drugs. These indicated the formation of a new complex for each drug. In DSC, pure olmesartan medoxomil showed melting endotherm at $183.07^{\circ} \mathrm{C}$, 
dapagliflozin at $69.43^{\circ} \mathrm{C}$, vildagliptin at $151.64^{\circ} \mathrm{C}$ and metformin at $232.30^{\circ} \mathrm{C}$. The complex OD showed a broad endothermic peak at $96.69{ }^{\circ} \mathrm{C}$, which was different from the endothermic peaks of its parent drugs e.g. olmesartan medoxomil $\left(183.07^{\circ} \mathrm{C}\right)$ and dapagliflozin $\left(69.43^{\circ} \mathrm{C}\right)$ indicating the formation of a new complex. Besides, complexes OV and OM also produced endothermic peaks at $111.97^{\circ} \mathrm{C}$ and $198.01^{\circ} \mathrm{C}$, respectively which were also different from their precursors. These differences also indicated the formation of new complexes as OV and OM (Figure 2).

Table 1. $R_{f}$ values of olmesartan medoxomil antidiabetic drugs and their complexes on TLC using methanol-chloroform (40:60) as mobile phase.

\begin{tabular}{lc}
\hline Item & $\mathbf{R}_{\mathbf{f}}$ value \\
\hline Olmesartan medoxomil (O) & 0.8 \\
Dapagliflozin (D) & 0.6 \\
Vildagliptin (V) & 0.9 \\
Metformin HCl (M) & 0.3 \\
OD complex & 0.7 \\
OV complex & 0.5 \\
OM complex & 0.4 \\
\hline
\end{tabular}

TGA thermograms were obtained from pure drugs and their complexes. The overlaid TGA thermograms are shown in figure 3 .
The molecular fragmentation pattern of olmesartan medoxomil is shown in figure 4. In TGA for pure olmesartan medoxomil, $20.17 \%$ degradation was observed at $243.53{ }^{\circ} \mathrm{C}$ which corresponds to first step release of medoxomil group form the drug (i.e. $\mathrm{m} / \mathrm{e} 558.22$ to $\mathrm{m} / \mathrm{e}$ 444.23) (Figure 3).The TGA thermogram was almost similar to molecular fragmentation of olmesartan medoxomil which indicates the single entity of the drug. ${ }^{15}$

The degradation pattern of pure dapagliflozin in TGA was found to be $21.57 \%$ and $38.59 \%$ at 279.53 ${ }^{\circ} \mathrm{C}$ and $327.85^{\circ} \mathrm{C}$, respectively (Figure 3) which supported the breakdown pattern published previously ${ }^{16}$ (Figure 5).

The degradation pattern of pure vildagliptin in TGA was also found as $8.18 \%$ and $16.41 \%$ at 164.83 ${ }^{\circ} \mathrm{C}$ and $243.53^{\circ} \mathrm{C}$, respectively (Figure 6) which supported the breakdown pattern published by Kumar et al. $^{17}$

Like other above mentioned drugs, pure metformin $\mathrm{HCl}$ also showed $20.08 \%$ degradation at $251.25{ }^{\circ} \mathrm{C}$ for the removal of $\mathrm{HCl}$ molecule from the entity, and $51.96 \%$ degradation at $300.47{ }^{\circ} \mathrm{C}$ for the removal of $-\mathrm{NH}_{2}-\mathrm{NH}$ group (Figures 3 and 7). ${ }^{18}$

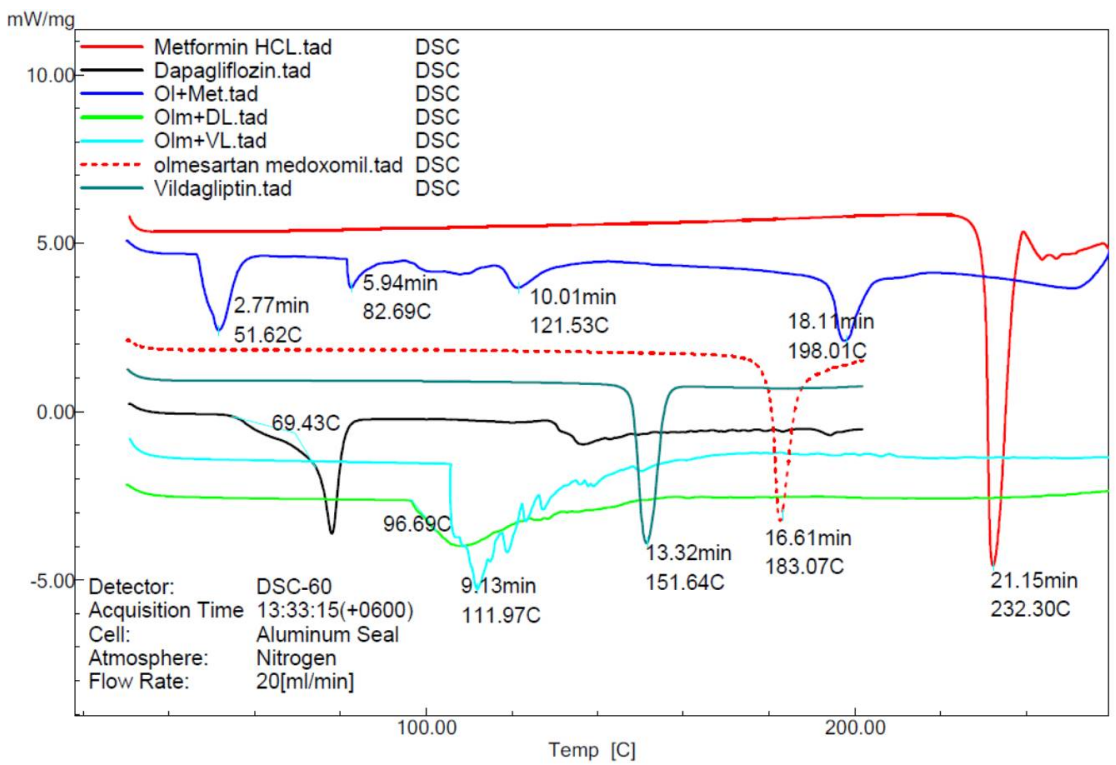

Figure 2. Overlaid DSC thermograms of olmesartan medoxomil, dapagliflozin, vildagliptin, metformin and their complexes. 


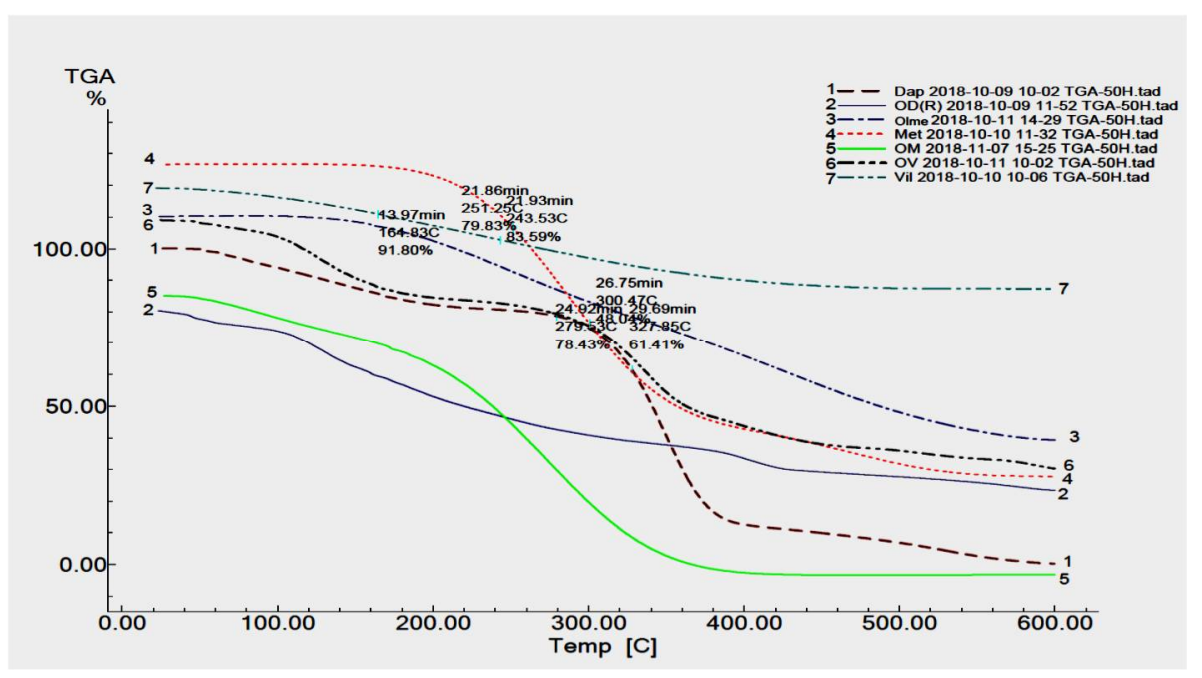

Figure 3.Overlaid TGA of pure drugs and their complexes.

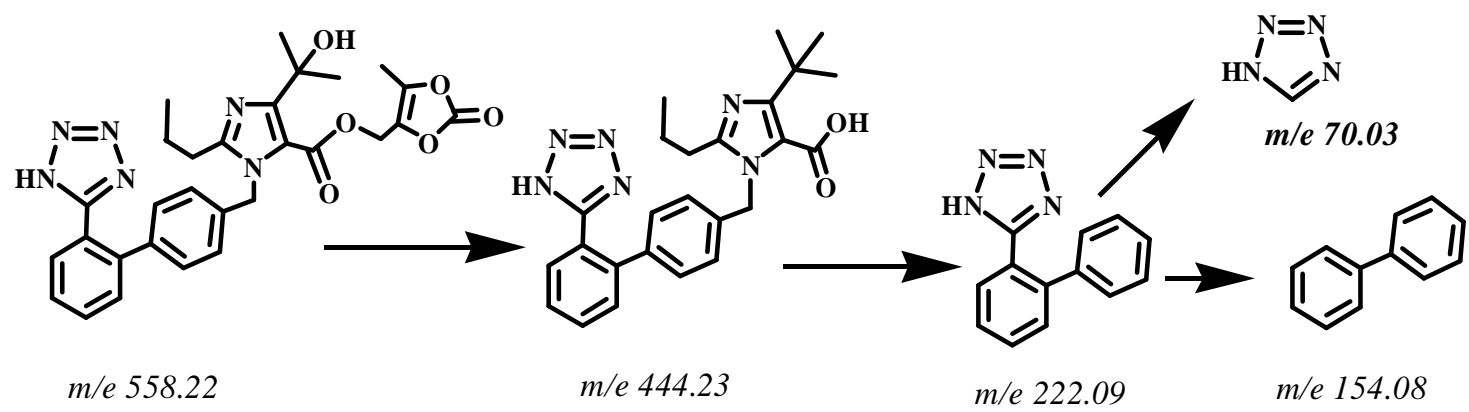

Figure 4. Degradation pattern of olmesartan medoxomil.

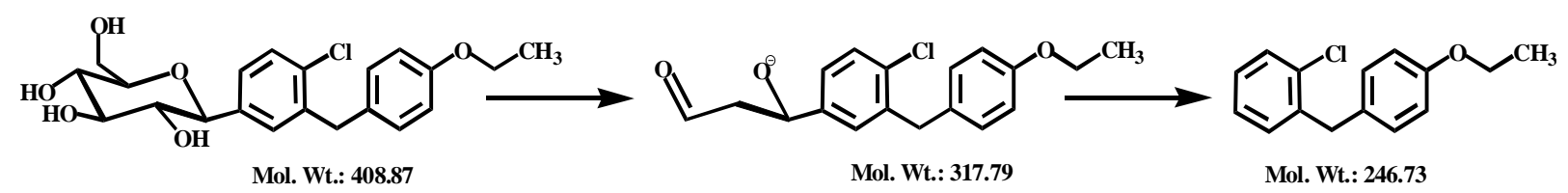

Figure 5. Degradation pattern of dapagliflozine.

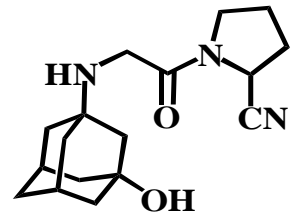

$m / e 305.42$

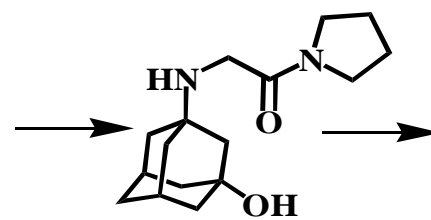

m/e 280.22

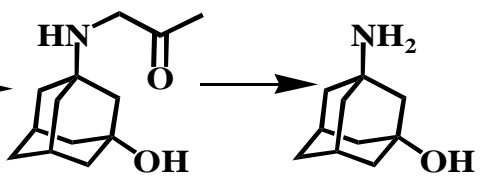

$m / e 226.17$ m/e 153.09

Figure 6. Degradation pattern of vildagliptin. 


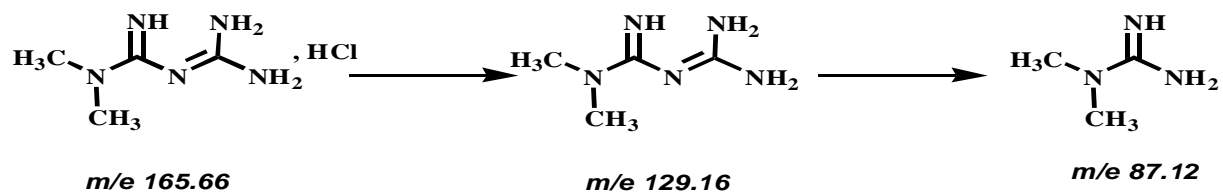

Figure 7. Degradation pattern of metformin $\mathrm{HCl}$.

The drug-drug complexes that were supposed to be formed, however, showed completely different degradation patterns. For OD, the thermogravimetric degradations were found to be $50.10 \%$ at $423.92{ }^{\circ} \mathrm{C}$ and $56.97 \%$ at $598.22{ }^{\circ} \mathrm{C}$ which are obviously different from parent pure drugs olmesartan medoxomil and dapagliflozin. These different patterns of degradation indicated the formation of different compound of OD (Figure 3).

For OM complex, $25.31 \%$ degraded at $211.31{ }^{\circ} \mathrm{C}$ and $81.32 \%$ at $592.70{ }^{\circ} \mathrm{C}$. These degradation patterns are also quite different from the parent drugs olmesartanmedoxomil and metformin (Figure 3). These differentiations allowed us to assume the formation of a good complex between olmesartanmedoxomil and metformin.
Like OD and OM, the other complex OV demonstrated degradations at $23.46 \%$ at $183.59{ }^{\circ} \mathrm{C}$, $33.84 \%$ at $300.86{ }^{\circ} \mathrm{C}$ and $78.74 \%$ at $599{ }^{\circ} \mathrm{C}$. This pattern suggested a complete different nature of $\mathrm{OV}$ from the parent drug olmesartan medoxomil and vildagliptin (Figure 3).

FT-IR is useful in providing information about the presence or absence of specific functional groups. If two pure samples display the same IR spectra, it can be concluded that they are the same compounds. Similarly, any shifts or disappearance of peaks indicate presence of a different compound. The IR spectrum obtained after drug-drug interaction was seen to demonstrate a new pattern of peaks compared to pure drug powder. The characteristic peaks of $\mathrm{OH}$

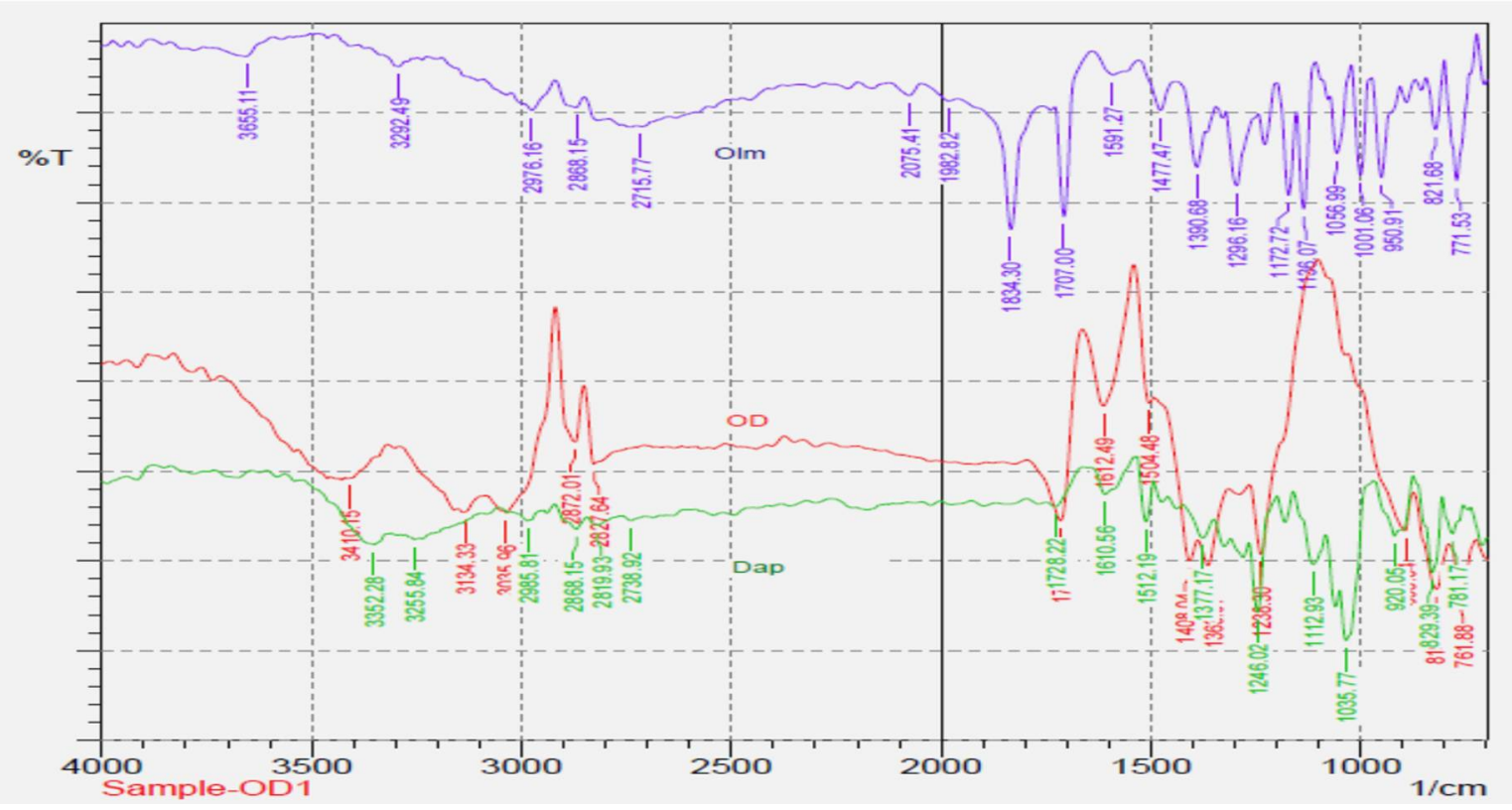

A 


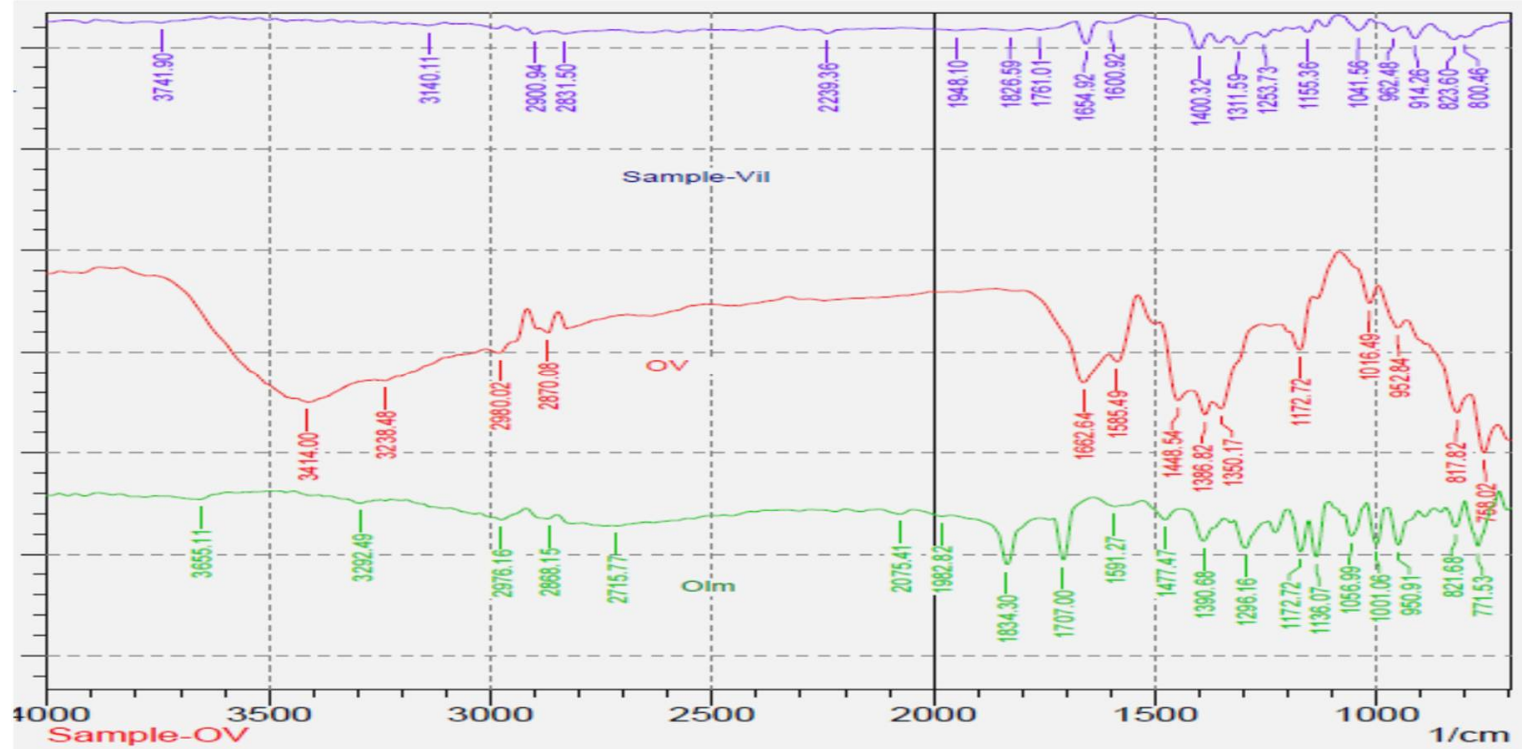

B

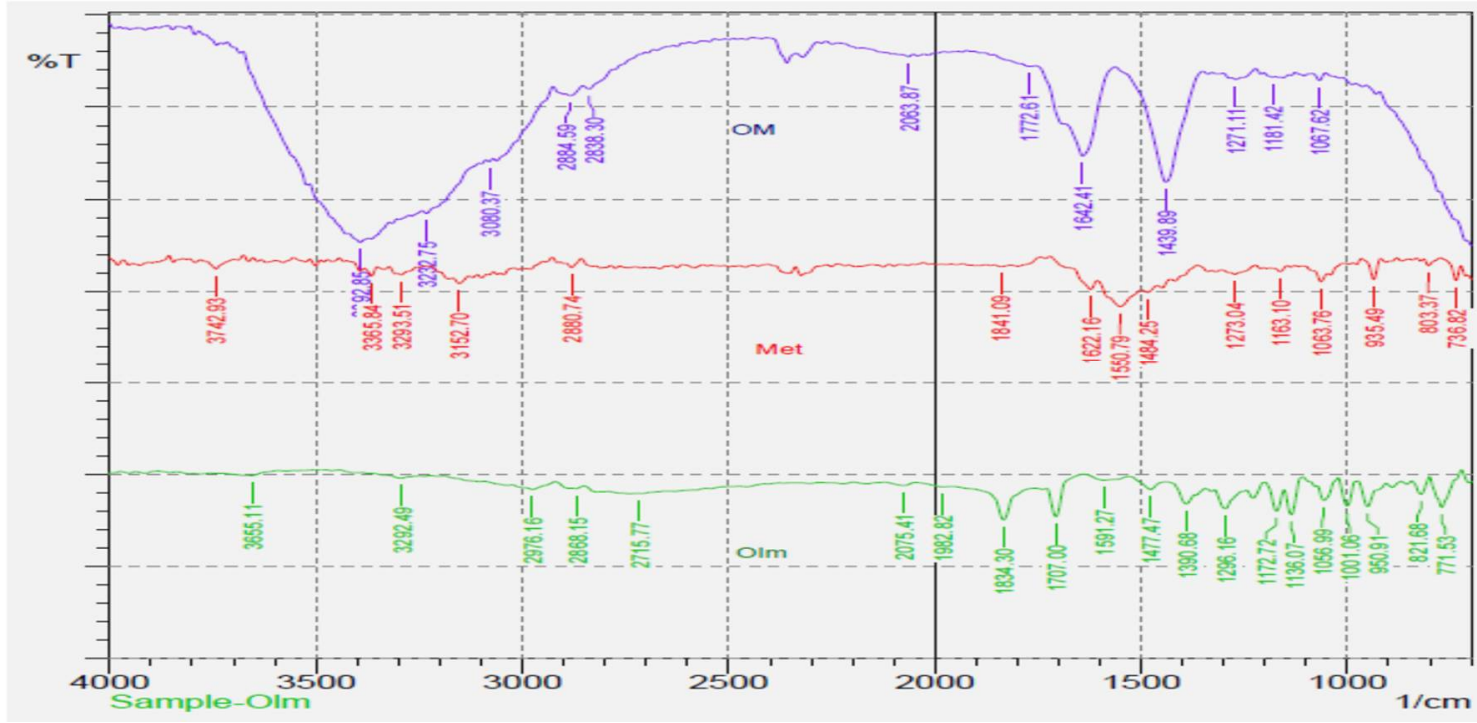

C

Figure 8. Overlaid FT-IR of olmesartan medoxomil and its complexes: (A) olmesartan medoxomil-dapagliflozin complex, OD, (B) olmesartan medoxomil-vildagliptin complex, $\mathrm{OV},(\mathrm{C})$ olmesartan medoxomil-metformin $\mathrm{HCl}$ complex, $\mathrm{OM}$.

stretching of olmesartan medoxomil, dapagliflozin, vildagliptin observed at $3655.11 \mathrm{~cm}^{-1}$ and 3352.28 $\mathrm{cm}^{-1}, 3741 \mathrm{~cm}^{-1}$, respectively which were found to be abolished in the IR spectra of OD and OV, and a single peak was seen at $3410.15 \mathrm{~cm}^{-1}$ for OD and $3414.00 \mathrm{~cm}^{-1}$ for OV. Likewise, the characteristic stretching peak of $-\mathrm{NH}_{2}$ of metformin seen at 3742.93 $\mathrm{cm}^{-1}$ which was obtained in the downfield at 3232.75 $\mathrm{cm}^{-1}$ for $\mathrm{OM}$ (Figure 8). These changes the absorption characteristics in the IR spectra indicated the complexation between the drugs.

\section{POSTULATED COMPLEXATION}

The postulations for the reactions are shown as follows. In suitable conditions, olmesartan medoxomil and dapagliflozin reacted with each other to obtain new complexes (Figure 9). ${ }^{19}$ 
According to Neerajet al. ${ }^{17}$ olmesartan medoxomil and vildagliptin interacted with one another by releasing water molecule in presence of acid to form new complexes as shown in figure 10.
During interaction of olmesartan medoxomil and metformin in presence of acidic conditions one molecule of water was released to form a complex which was supported by TGA. The postulated reaction is shown in figure 11 .

$$
\text { Olmesartan medoxomil + Dapagliflozin } \underset{-\mathrm{C}_{2} \mathrm{H}_{5} \mathrm{OH}}{\stackrel{(\mathrm{H}+, \text { catalysts })}{\longrightarrow}} \text { Complex } 1+\text { Complex } 2
$$
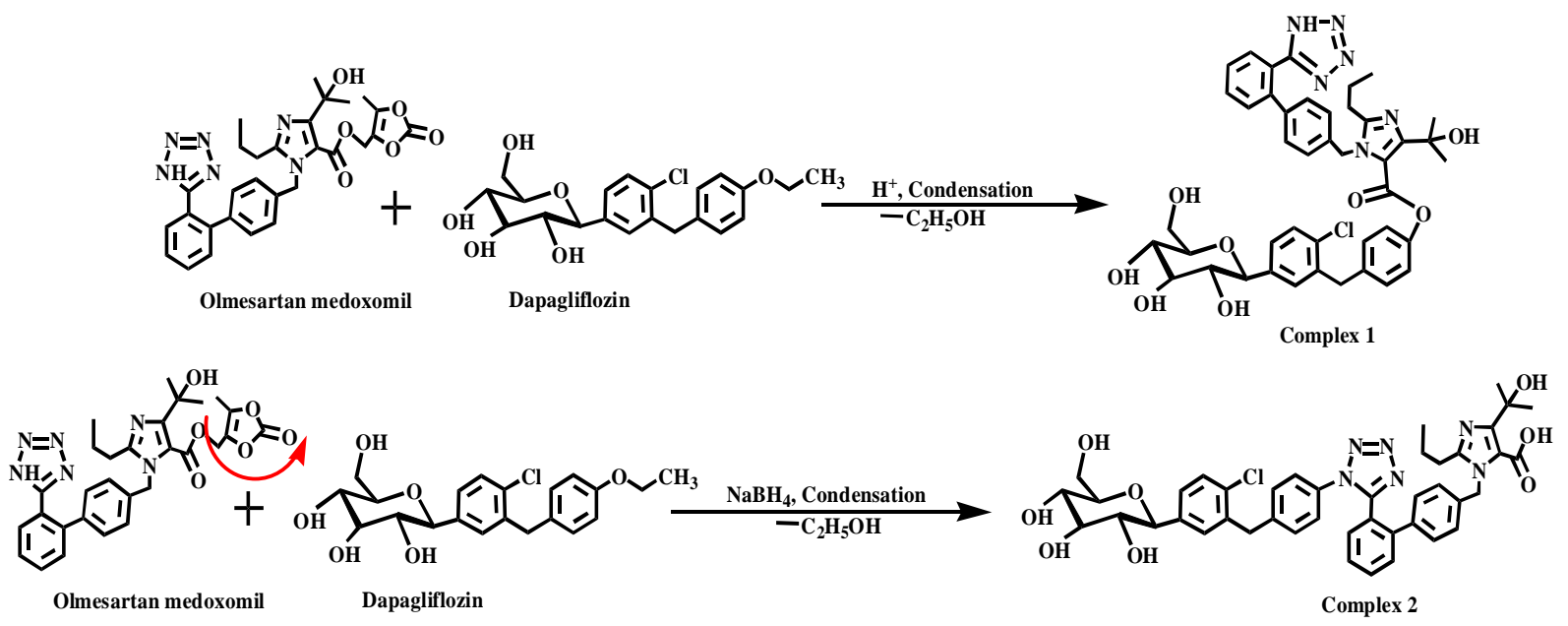

Figure 9. Postulated complexation patterns between olmesartan medoxomil and dapagliflozin.

Olmesartan medoxomil + Vildagliptin $\frac{\left(\mathrm{H}^{+}, \mathrm{H}_{2} \mathrm{O}\right)}{\text { Condensation }} \longrightarrow$ Complex $3+$ Complex 4

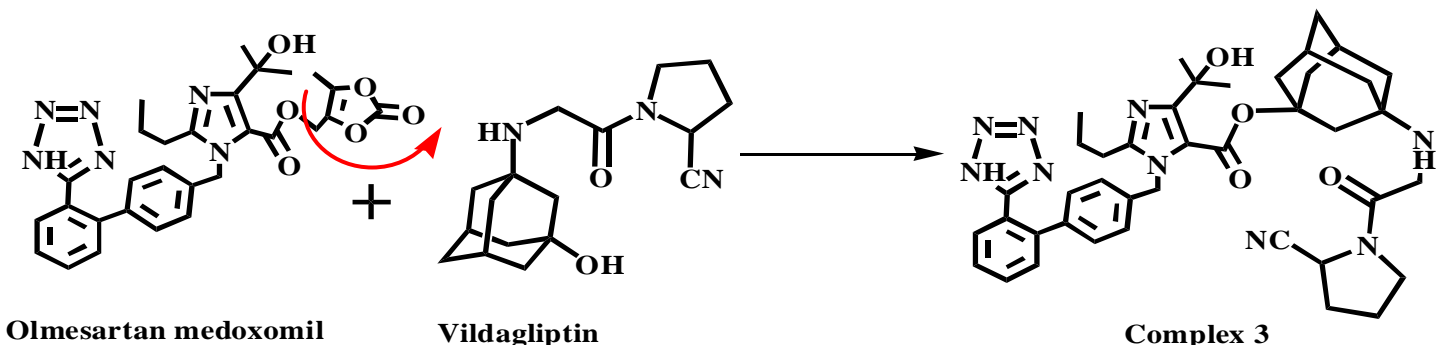

Olmesartan medoxomil

Vildagliptin

Complex 3

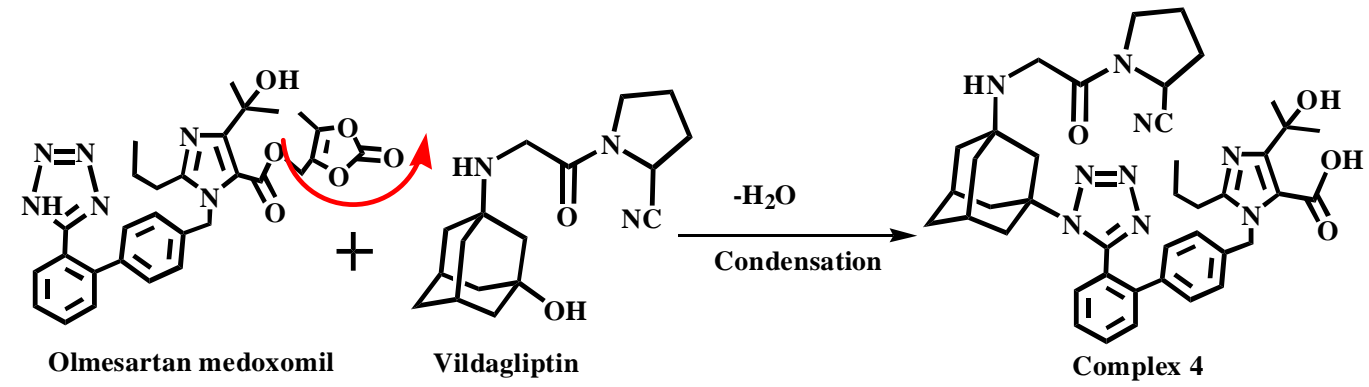

Figure 10. Postulated complexation patterns between olmesartan medoxomil and vildagliptin. 


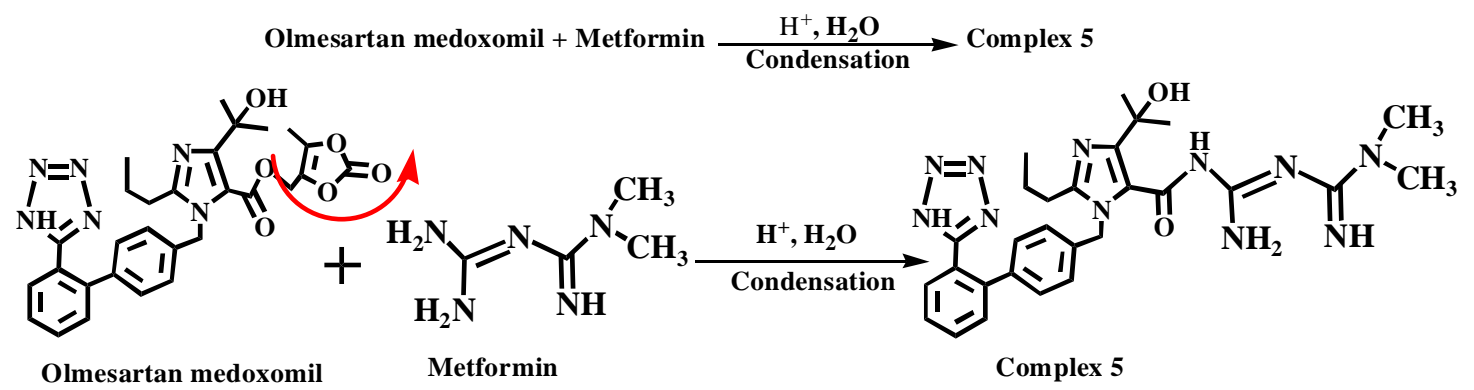

Figure 11. Postulated complexation patterns between olmesartan medoxomil and metformin.

\section{CONCLUSION}

Antihypertensive drug olmesartan medoxomil was allowed to react with three antidiabetic drugs namely dapagliflozin, vildagliptin and metformin in acidic condition. It was found that olmesartan medoxomil reacted with these antidiabetic drugs and produced complexes which were justified by studying their thermochemical properties e.g. DSC, TGA and various chromatographic techniques like TLC and HPLC as well as by IR spectrophotometry. From this study, it is obvious that concomitant use of these antidiabetic drugs with antihypertensive drug (olmesartan medoxomil) has a strong probability to produce complexes in the stomach. However, their impacts on the biological activities and/or toxicity profile could not be established at this moment. Further comprehensive studies, including those in in vivo model will be required to establish the beneficial and/or untoward effects during concomitant uses of these tested drug molecules.

\section{REFERENCES}

1. Bista, D., Palaian, S., Shankar, P.R., Prabhu, M.M., Paudel, R. and Mishra, P. 2006. Understanding the essentials of drug interactions: a potential need for safe and effective use of drugs. Kathmandu Univ. Med. J. 4, 421-430.

2. Kerr, D., MacDonald, I.A., Heller, S.R. and Tattersall, R.B. 1990. $\beta$-adrenoceptor blockade and hypoglycaemia. A randomised, double-blind, placebo controlled comparison of metoprolol CR, atenolol and propranolol LA in normal subjects. Br. J. Clin. Pharmacol. 29, 685-693.

3. Cruciol-Souza, J.M. and Thomson, J.C. 2006. Prevalence of potential drug-drug interactions and its associated factors in a Brazilian teaching hospital. J. Pharm. Pharm. Sci. 9, 427433.
4. Amirthalingam, S. and Vaidhun, B.H. 2010. Drug Interactions- a view on doctors. Ann. Biol. Res. 1, 61-69.

5. International Diabetes Federation (IDF), IDF Diabetes Atlas, 6th Edition. Brussels: International Diabetes Federation. 2013 (www.idf.org). Accessed on 27 June 2019.

6. Vlassara, H. and Striker, G.E. 2013. Advanced glycation end products in diabetes and diabetic complications. Endocrinol. Metab. Clin. N. Am. 42, 697-719.

7. Banerjee, M. and Vats, P. 2014. Reactive metabolites and antioxidant gene polymorphisms in type 2 diabetes mellitus. Redox Biol. 2, 170-177.

8. Shrestha, P. and Ghimire, L. 2012. A review about the effect of life style modification on diabetes and quality of life. Glob. J. Health Sci. 4, 185-90.

9. Mitra, S.K., Sundaram, R., Venkataranganna, M.V. and Gopumadhavan, S. 1999. Pharmacokinetic interaction of diabecon (D-400) with rifampicin and nifedipine. Eur. J. Drug Metab. Pharmacokinet. 24, 79-82.

10. Grossman, E., and Messerli, F.H. 2008. Hypertension and diabetes. Adv. Cardiol. 45, 82-106.

11. Nussberger, J. and Koike, H. 2004. Antagonizing the angiotensin II subtype 1 receptor: a focus on olmesartan medoxomil. Clin. Ther. 26, Suppl. A: A12-20.

12. Macdonald, F.R., Peel, J.E., Jones, H.B., Mayers, R.M., Westgate, L., Whaley, J. M. and Poucher, S.M. 2010. The novel sodium glucose transporter 2 inhibitor dapagliflozin sustains pancreatic function and preserves islet morphology in obese, diabetic rats. Diabetes Obes. Metab. 12, 1004-1012.

13. https://en.wikipedia.org/wiki/Vildagliptin (Accessed on 27/6/2019)

14. Lund, S.S., Tarnow, L., Stehouwer, C.D., Schalkwijk, C.G., Frandsen, M., Smidt, U.M., Pedersen, O., Parving, H.H. and Vaag, A. 2007. Targeting hyperglycaemia with either metformin or repaglinide in non-obese patients with type 2 diabetes: results from a randomized crossover trial. Diabetes Obes. Metab. 9, 394-407. 
15. Shankar, G., Pragney, D. and Ramakrishna, S. 2014. Simultaneous determination of atrovastatin calcium and olmesartan medoxomil in rat plasma by liquid chromatography electrospray ionization tandem mass spectrometry and its application to pharmacokinetics in rats. Int. J. Pharm. Pharm. Sci. 6, 464-468.

16. Amit, S.K., Iain, G.R., Scott, O., Christopher, L.S., Ernesto, C., Kirk, R.H., Abdul, E.M., Deepak, K.D., Jae, S.L., Yasuhiro, N., John, P.O'D., Jason, B., and Shawn, P.H. 2005. A comprehensive listing of bioactivation pathways of organic functional groups. Curr. Drug Metab. 6, 161-225.

17. Neeraj, K., Subba, R.D., Gurmeet, S., Kadirappaa, A., Shailendra, K.D. and Pramod K. 2016. Identification, isolation and characterization of potential process-related impurity and its degradation product in vildagliptin. $J$. Pharm. Biomed. Anal. 119, 114-121.
18. Agrawal, Y.K., Gogoi, P.J., Manna, K., Bhatt, H.G. and Jain, V.K. 2010. A supercritical fluid chromatography/tandem mass spectrometry method for the simultaneous quantification of metformin and gliclazide in human plasma. Indian J. Pharm. Sci. 72, 50-57.

19. Dams, I., Ostaszewska, A., Puchalska, M., Chmiel, J. Cmoch, P., Bujak, I., Białońska, A. and Szczepek, J.W. 2015. Synthesis and physicochemical characterization of the process-related impurities of olmesartan medoxomil. Do 5(Biphenyl-2-yl)-1-triphenylmethyltetrazole intermediates in sartan syntheses exist? Molecules 20, 21346-21363. 